A Typology of Propagation of Technology and Social Preferences in the Process of Economic Development: An Input-Output Approach

EDUARDO A. HADDAD

WESLEM R. FARIA

JOAQUIM J. M. GUILHOTO

Working PAPER SERIES № 2011-10 
DEPARTMENT OF ECONOMICS, FEA-USP

WORKING PAPER № 2011-10

\title{
A typology of Propagation of Technology and Social Preferences in the Process of Economic Development: An Input-Output Approach
}

\author{
Eduardo A. Haddad (ehaddad@usp.br) \\ Weslem R. Faria (weslem_faria@yahoo.com.br) \\ Joaquim J. M. Guilhoto (guilhoto@usp.br)
}

Research Group: NEREUS - Núcleo de Economia Regional e Urbana

\begin{abstract}
:
In this paper we look at the interplay of technology and social preferences in different stages of economic development. We use a set of input-output tables for 32 different countries, published by OECD. The tables refer to the period 1996-2001 and were consolidated in 48 sectors so that structural comparisons were possible. Through the use of the fields of influence of structural change for partitioned input-output systems, we confirm that, for different levels of per capita GDP, technological progress is an important element to drive output growth. However, as an economy evolves, our dataset also confirm that the composition of final demand, which reveals social preferences in a static way, move away from agricultural and manufacturing to services activities. Such structural changes favor sectors with weaker output multipliers generating a force that helps driving income convergence among countries.
\end{abstract}

Keywords: social preferences, economic development, input-output

JEL Codes: 010, R15. 


\title{
A Typology of Propagation of Technology and Social Preferences in the Process of Economic Development: An Input-Output Approach
}

\author{
Eduardo A. Haddad, Weslem R. Faria and Joaquim J. M. Guilhoto
}

\begin{abstract}
In this paper we look at the interplay of technology and social preferences in different stages of economic development. We use a set of input-output tables for 32 different countries, published by OECD. The tables refer to the period 1996-2001 and were consolidated in 48 sectors so that structural comparisons were possible. Through the use of the fields of influence of structural change for partitioned input-output systems, we confirm that, for different levels of per capita GDP, technological progress is an important element to drive output growth. However, as an economy evolves, our dataset also confirm that the composition of final demand, which reveals social preferences in a static way, move away from agricultural and manufacturing to services activities. Such structural changes favor sectors with weaker output multipliers generating a force that helps driving income convergence among countries.
\end{abstract}

\section{Introduction}

More than half a century has passed since Chenery and Watanabe (1958) first drew the attention to the use of input-output tables as a way to describe and compare structural characteristics of different economies. Since then, a body of literature has emerged, attempting to develop alternative approaches to uncover similarities and differences in the structure of countries and regional economies over time. As a consequence, different methods of comparative structural analysis were explored; it was hoped that the complementarities among them might result in a better appreciation of the full dimensions of differences and similarities that might exist. Moreover, the results served the purposes not only to reveal the nature of interdependence but also to shed light on the mechanisms of growth whose understanding requires an empirical knowledge of the nature of such interdependence.

Neoclassical growth models share the same basic general equilibrium structure (Barro and Sala-i-Martin, 1995). First, households own the inputs and assets of the economy, including ownership rights in firms, and choose the fractions of their income to consume and save (invest). Each household determines how many children to have, whether to join the labor force, and how much to work. Second, firms hire inputs, such as capital and labor, and use these inputs to produce goods that they sell to households 
or other firms. Firms have access to technology - which may evolve over time - that allows them to transform inputs into output. Third, markets exist on which firms sell goods to households or other firms and on which households sell the inputs to firms. The quantities demanded and supplied determine the relative prices of the inputs and the produced goods (p. 14).

In this context, social preferences are revealed in the allocation of resources of a given society. They are partially portrayed in input-out tables, which measure annual flows that depend on the total amount and pattern of domestic demand, on the composition of imports and exports, on physical input-output proportions, and on relative prices. ${ }^{1}$ Information on household consumption and investments provides a static picture of households' intertemporal preferences. In an open economy with government, the composition of imports and exports reveals the optimization decision based on a vector of domestic and foreign prices. And the share of government expenditures in total final demand gives information on the society's preferences for public and private goods.

In this paper we look at the interplay of technology and social preferences in different stages of economic development. We use a set of input-output tables for 32 different countries, published by OECD (Yamano and Ahmad, 2006). The tables refer to the period 1996-2001 and were consolidated in 48 sectors so that structural comparisons were possible.

Through the use of the fields of influence of structural change for partitioned inputoutput systems, we confirm that, for different levels of per capita GDP, technological progress is an important element to drive output growth. However, as an economy evolves, our dataset also confirms that the composition of final demand, which reveals social preferences in a static way, move away from agricultural and manufacturing to services activities. Such structural changes favor sectors with weaker output multipliers generating a force that helps driving income convergence among countries.

These results, based on a cross-section of countries, join other studies that have attempted to find patterns of economic development. As such, they should not be

\footnotetext{
${ }^{1}$ Chenery and Clark (1959, p. 202).
} 
regarded too ambitiously. As Aghion and Williamson (1998) pointed out, hypotheses generated from descriptive studies of patterns of growth should be tested from a broader perspective. While in the case of the Kuznets hypothesis - which suggests that, in the long run, modern economic growth would generate an early industrialization phase of rising inequality, followed eventually by a mature industrialization phase of declining inequality - traditional literature has focused on establishing or rejecting the Kuznets curve as a stylized fact, more effort should be directed to uncover the sources of inequality.

The objectives of this paper are twofold. On one hand, we bring additional evidence for the descending track of Kuznets inverted $U$ curve, based on a sample of middle and high-income countries with different stages of industrialization maturing. On the other hand, we look at the interdependence of technology and social preferences as a possible source of inequality change. While the results are to be qualified, we hope they will serve to shed light on the mechanisms of growth and to stimulate further work in this line of research.

The paper is organized as follows. Section 2 discusses certain background issues on the fields of influence of structural changes, while Section 3 presents the research design and data sources. Section 4 provides results of the proposed methodology, and a final section offers an interpretative commentary on the empirical analysis.

\section{Background issues}

The conventional input-output model is given by the system of matrix equations (Miller and Blair, 1985):

$x=A x+f$

$x=(I-A)^{-1} f=B f$

where $x$ and $f$ are respectively the vectors of gross output and final demand; and $A$ consists of input coefficients $a_{i j}$ defined as the amount of product $i$ required per unit of product $j$ (in monetary terms), for $i, j=1, \ldots, \mathrm{n}$. 
Let us consider systems (1) and (2) for $r=1, \ldots, \mathrm{R}$ different countries, so that:

$x^{r}=A^{r} x^{r}+f^{r}$

$x^{r}=\left(I-A^{r}\right)^{-1} f^{r}=B^{r} f^{r}$

The field of influence approach [Sonis and Hewings (1989) and Sonis et al. (1993)] can be used, in this case, to evaluate structural changes both in $A^{r}$ and $f^{r}$. Through the use of the fields of influence of structural change in input-output system, one can estimate the changes in output created by the propagation of structural changes in the available technology and social preferences.

Let us assume that, for each country $r$, some changes have occurred between time periods $O$ and $t$, these structural changes in technology and social preferences can be represented, respectively, as the following matrix (5) and vector (6):

$E^{r}=\left[E_{i j}^{r}\right]$

$e^{r}=\left[e_{i}^{r}\right]$

where $E_{i j}^{r}$ and $e_{i}^{r}$ represent changes in direct coefficients and final demand flows, for $i, j$ $=1, \ldots, \mathrm{n}$.

At time $t$, a new matrix of direct coefficients and a new vector of final demand may be revealed for country $r$ :

$A^{r}+E^{r}=\left[A_{i j}^{r}+E_{i j}^{r}\right]$

$f^{r}+e^{r}=\left[f_{i}^{r}+e_{i}^{r}\right]$

For (7), there is a corresponding Leontief inverse $B^{r}\left(E^{r}\right)=\left[I-A^{r}-E^{r}\right]^{-1}$. 
In this case, the change in gross output, $\Delta x^{r}$, can be calculated as:

$\Delta x^{r}=x^{r}\left(E^{r}\right)-x^{r}=\left[B^{r}\left(E^{r}\right)-B^{r}\right]\left[f^{r}\left(e^{r}\right)-f^{r}\right]$

In other words, the change in output can be approximated by the composition of a "technological effect", given by $\left[B^{r}\left(E^{r}\right)-B^{r}\right] f^{r}$ and a "social preferences effect", given by $B^{r}\left[f^{r}\left(e^{r}\right)-f^{r}\right]$. Thus,

$\Delta x^{r} \approx\left[B^{r}\left(E^{r}\right)-B^{r}\right] f^{r}+B^{r}\left[f^{r}\left(e^{r}\right)-f^{r}\right]$

We will use equation (10) as the benchmark for our simulations. Following the tradition in line with Kuznets, in which cross-country data are used to reveal patterns of economic development, a set of comparable input-output tables will be used to describe the existing relationship between technology, social preferences and economic development.

\section{Research Design and Data Sources}

In order to make the results comparable, we proceed with a normalization of the preferences vectors (computing a country-specific standard unit of final demand) and, subsequently, with a normalization of country technologies (by normalizing the multiplier effects by a country's given technology). Thus, the analysis reaches the desired property of "metric homogeneity". This eliminates potential biases associated with the choice of the weights in decomposition analysis (see Hoen, 1999).

We depart from a set of input-output tables for 32 countries. The choice of countries was restricted by data availability as we have relied on a data set provided by OECD (Yamano and Ahmad, 2006). The adjusted tables ended up with 48 sectors and the benchmark years ranged from 1996 to $2001{ }^{2}$

In our computations, we have used equation (10) as the starting point to infer the structural role played by technology and social preferences in the process of economic

\footnotetext{
${ }^{2}$ See a description of the main characteristics of the database in the annex.
} 
development. For the first part of equation (10), $\left[B^{r}\left(E^{r}\right)-B^{r}\right] f^{r}$, which attempts to isolate the "technological effect", we have used, for country $r$, its specific standard unit of final demand pre-multiplied by the different country-specific Leontief inverse matrices. In other words, we have computed the total multiplier effect of a normalized final demand vector for different technological contexts. Thus, for country $r$ we have:

$x^{r / s}=\left(I-A^{s}\right)^{-1} f^{r}, \forall s=1, \ldots, R$

Where $x^{r / s}$ denotes a vector of output associated with social preferences in $r$ given the available technology in $s$.

For the second part of equation (10), $B^{r}\left[f^{r}\left(e^{r}\right)-f^{r}\right]$, we have followed a similar procedure. Each country-specific Leontief inverse was post-multiplied by each of the $\mathrm{R}$ vectors of normalized final demand, such that:

$x^{s / r}=\left(I-A^{r}\right)^{-1} f^{s}, \forall s=1, \ldots, R$

Where $x^{s / r}$ stands for the vector of output associated with the social preferences in each country $s$ given the available technology in $r$.

At the end of this procedure we were able to construct a matrix, $M_{R x R}$, of crosstechnology and cross-preference multipliers. A typical element of such matrix, $m_{r s}$, reveals the output multiplier associated with the interaction of the technology of country $r$ and the social preferences of country $s$.

A standardization of matrix $M$ is needed as a final step to make adequate cross-country comparisons. We proceeded with the normalization of the country technologies through the row standardization of $M$ using its diagonal elements. Thus, the relevant estimates will be:

$\bar{m}_{r s}=\frac{m_{r s}}{m_{r r}}, \forall r, s=1, \ldots, R$

The column average of the elements of $\bar{M}$ is given by: 


$$
\bar{m}_{\cdot s}=\sum_{r=1}^{R} \frac{\bar{m}_{r s}}{R}
$$

It represents the outcome of the simulations of the interactions of country s' social preferences with the whole set of available technologies, i.e. the average preferences multiplier (APM) for country $s, \bar{m}_{\cdot s}$, attempts to capture the role played by its own social preferences in different technological contexts.

Likewise, the row average of the elements of $\bar{M}$ is given by:

$\bar{m}_{r .}=\sum_{s=1}^{R} \frac{\bar{m}_{r s}}{R}$

It represents the outcome of the simulations of the interactions of country $r$ 's technology with the whole set of available social preferences. Thus, for each country $r$, there will be an average technology multiplier (ATM), $\bar{m}_{r}$, which attempts to capture the role of country $r$ 's technology in different social preferences contexts.

The following analysis will use both the APM and the ATM to reveal structural features of the selected countries in order to unravel, in an input-output framework, the role played by technology and social preferences in the process of economic development.

\section{Results}

Figure 1 presents the results of the international cross-section analysis of the APM, which measures the relationship of a society's preference (given by the structure of its final demand) with the available technology (given by the input-output relations) throughout our sample. Per capita GDP statistics were used to rank the countries according to their development level. ${ }^{3}$

There appears a clear negative relation between per capita GDP and the APM. In general, countries with higher per capita GDP tend to have a lower APM. Since more

\footnotetext{
${ }^{3}$ The authors are aware the use of per capita GDP as a measure of economic development oversimplifies the problem.
} 
developed economies tend to have higher levels of GDP per capita than countries in development process and given the nature of such multipliers, a more thorough analysis of the structure of final demand for the different countries may bring additional insights for better understanding of this result.

\section{Figure 1. Relation between Per Capita GDP and Average Preferences Multipliers}

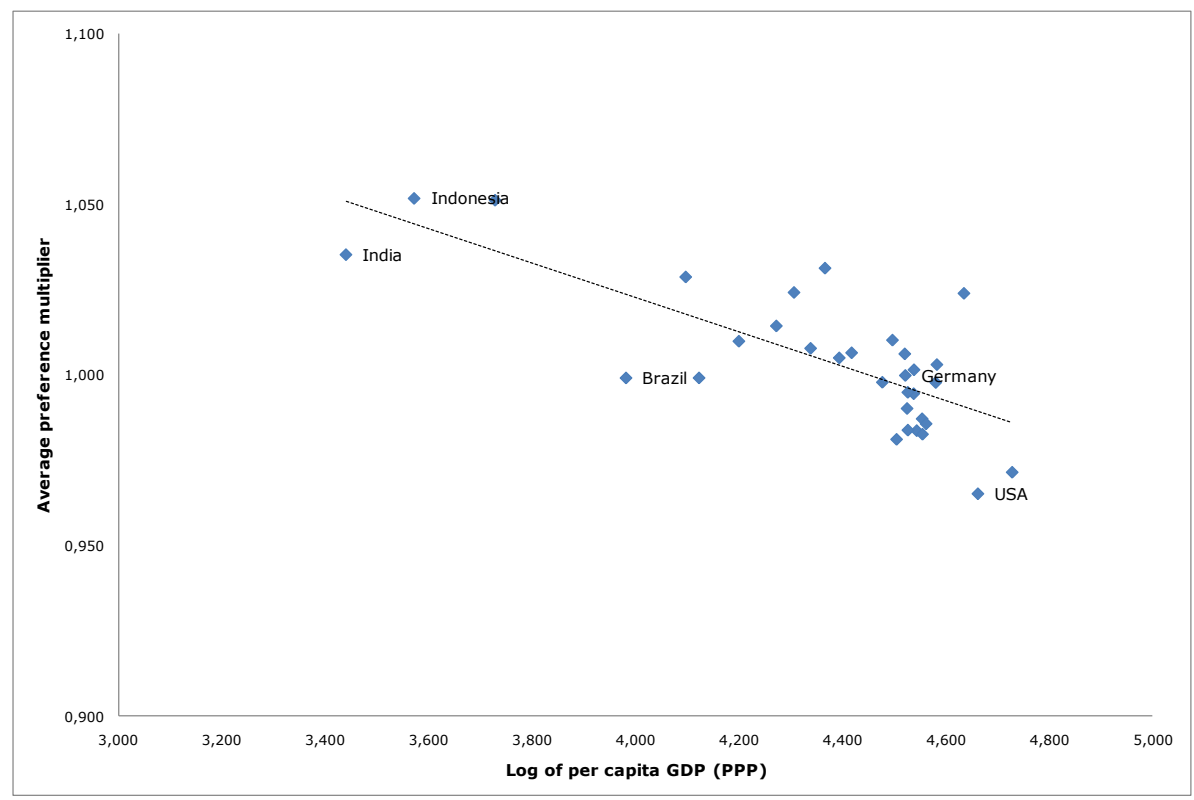

Figure 2 presents the shares of the three macro-sectors - primary, secondary and tertiary - in the composition of final demand in each country of the sample. ${ }^{4}$ We kept the hierarchy of per capita GDP in the x-axis. "Trend lines" were fitted to facilitate visualization of the general patterns. Overall, countries with higher per capita GDP present an increasing share of tertiary goods in their final demand vector, and corresponding decreasing shares of primary and secondary goods.

Figure 3 shows the input-output weighted output multipliers for the same aggregate sectors in each country, using the country-specific tables. The results reveal a pattern in which the multipliers of the tertiary sector are systematically lower than those for the primary and secondary sectors. Combined with the results provided in Figure 2, these two facts that emerge from the data used in this research - namely, (i) economies with higher per capita GDP tend to present stronger concentration in their final demand components in services, and (ii) tertiary activities tend to have lower multiplier effects -

\footnotetext{
${ }^{4}$ For presentation purposes, the 48 sectors were aggregated in the three usual categories of analysis.
} 
suggest that structural changes in social preferences a an economy evolves tend to be accompanied by lower second-order growth effects via sectoral linkages.

Figure 2. Sectoral Shares in Final Demand

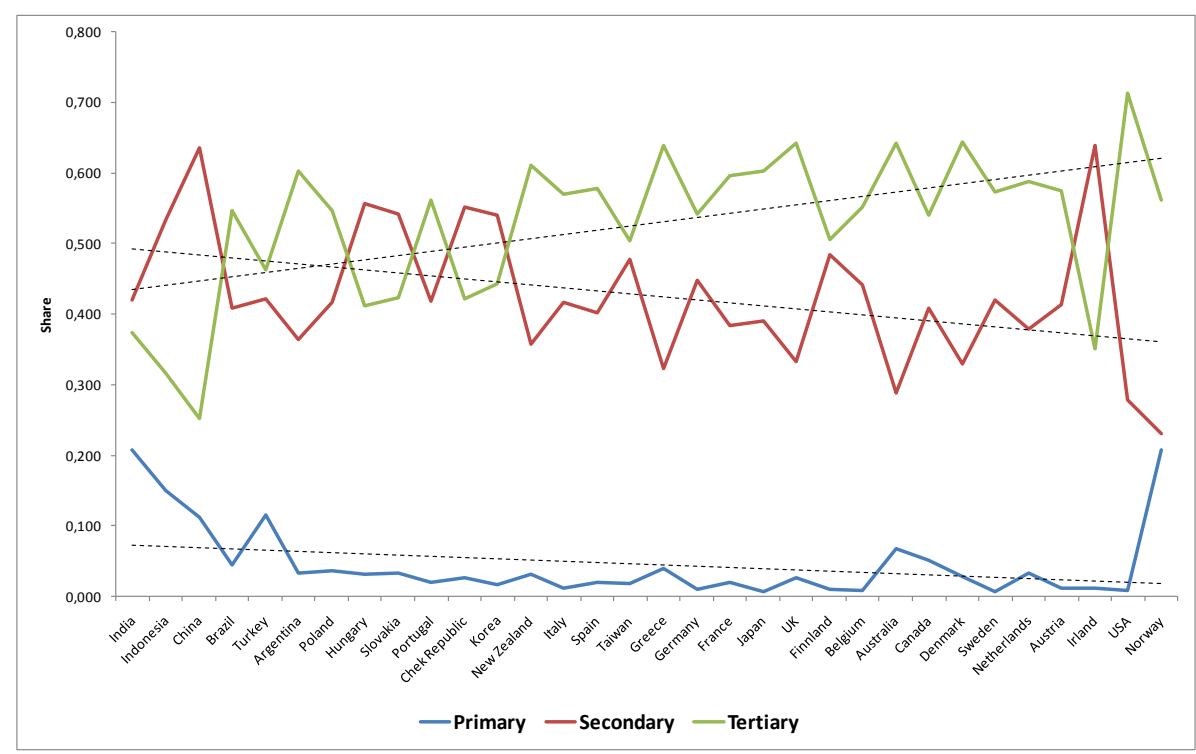

Figure 3. Weighted Input-output Multipliers

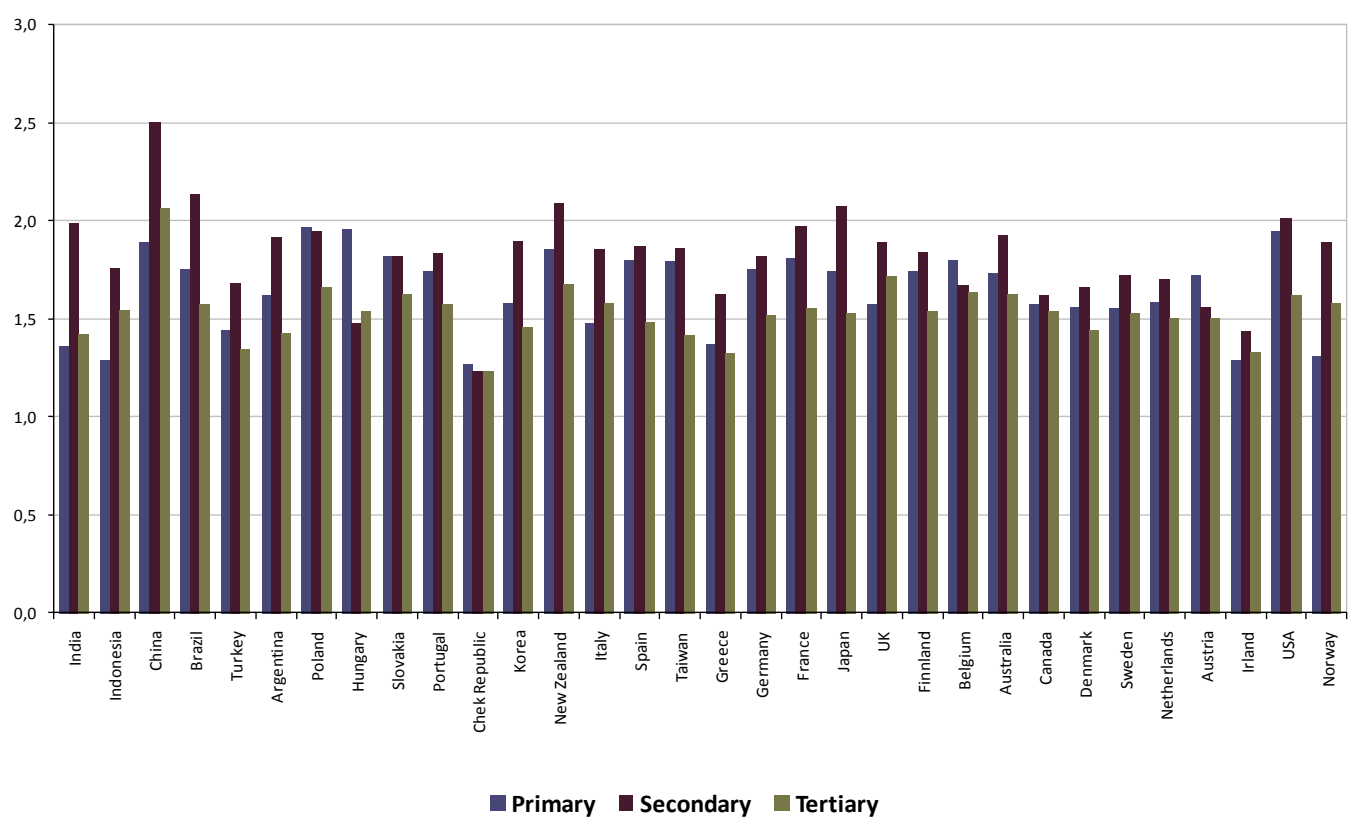


The second point of interest in our international cross-section study is to look at the relationship between technological progress and growth from a structural perspective. This is achieved by considering the information presented in Figure 4, which shows the results for the ATM for the countries in the sample. The ATM is a measure of performance technology of a country given to the structure of final demand of other countries.

There appears a positive relation between per capita GDP and the ATM. In general, countries with higher per capita GDP tend to have a higher ATM. Such result can be explained by technological process of structuring of the countries over time. The developed countries had a more robust process of industrialization and earlier in relation to developing countries. Moreover, in developing countries the industrialization process was marked by large government intervention, often unbalanced in terms of sectors and space.

Figure 4. Relation between Per Capita GDP and Average Technology Multipliers

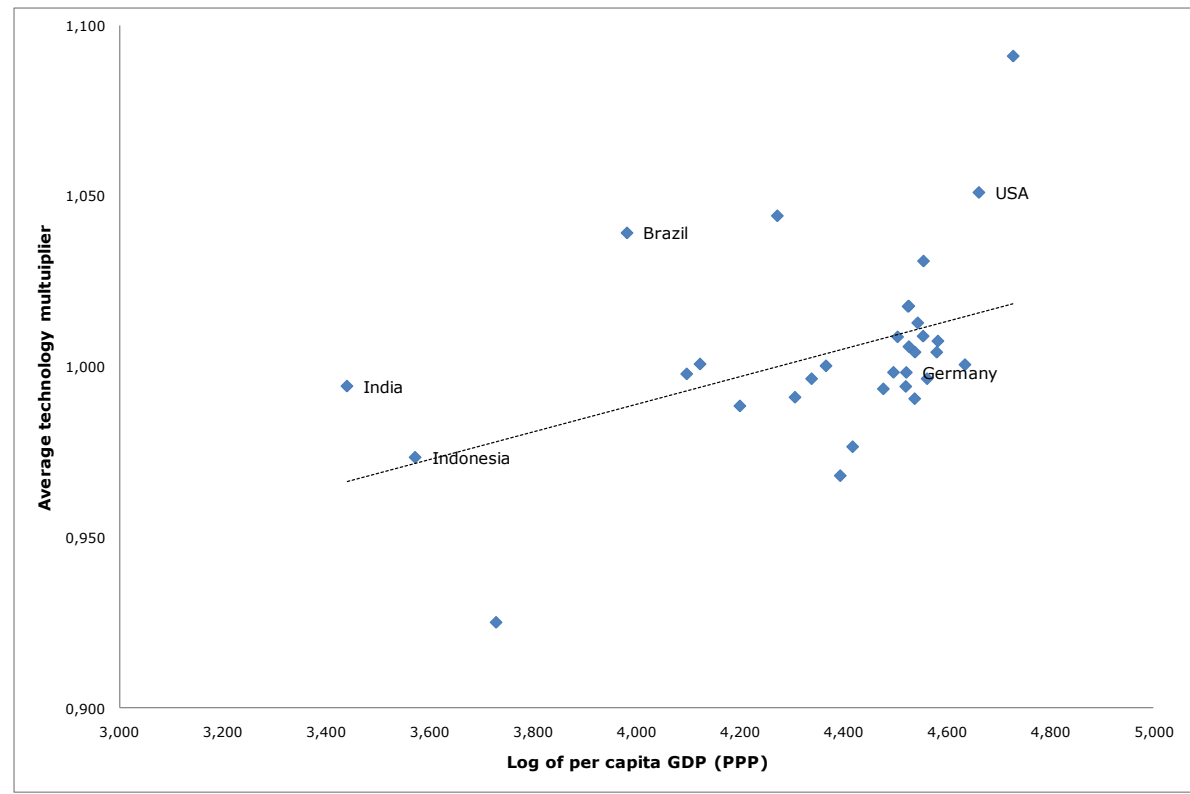




\section{Conclusions}

In this paper we look at different stages of development using a cross-section analysis of countries with different levels of per capita GDP. For that, we use information about input-output matrices that allow us to employ a detailed analysis of the economic structure of the countries. The main idea focuses on a set of projections of the relation of the society's social preference, given by the structure of final demand, against the worldwide available technology, given by the Leontief inverse matrix for the different countries.

The Kuznets idea was addressed using a cross-country analysis to identify patterns of development between countries with different stages of industrial maturity. One of the results indicates a pro-convergence relation among the per capita GDP and the average preferences multiplier (APM). Looking at the sectoral economic structure of the countries we realize that economies with higher per capita GDP tend to present stronger concentration in their final demand components in services, activities which tend to have lower multiplier effects. The other result indicates a positive relation between per capita GDP and the average technology multiplier (ATM). The explanation for this result may be linked to institutional and historical factors associated with the industrialization process of the countries over time. Finally, the structural features revealed in this study remain to be empirically tested in growth models. 


\section{References}

AGHION, P.; WILLIAMSON, J. Growth, Inequality and Globalization: Theory, History and Policy. Cambridge: Cambridge University Press, 1998.

BARRO, R. J.; SALA-I-MARTIN, X. Economic Growth. Nova Iorque: McGraw Hill, Inc., 1995.

CHENERY, H. B.; CLARK, P. G. Interindustry Economics. Nova Iorque: John Wiley e Sons, 1959.

CHENERY, H. B.; WATANABE, T. International Comparisons of the Structure of Production. Econometrica, v. 26, n. 4, p. 487-521, out. 1958.

HOEN, A. An Input-Output Analysis of European Integration. Amsterdam: NorthHolland, 2002.

KUZNETS, S. Economic Growth and Income Inequality. American Economic Review, v. 45, p.1-28, 1955.

MILLER, R. E.; BLAIR, P. D. Input-output Analysis: Foundations and Extensions. Englewood Cliffs, New Jersey: Prentice-Hall, Inc., 1985.

SONIS, M.; HEWINGS, G. J. D. Error and Sensitivity Input-Output Analysis: A New Approach. In: Miller, R. E., Polenske, K. R. \& Rose, A. Z. (eds.). Frontiers of InputOutput Analysis. New York, Oxford University Press, 1989.

SONIS, M.; HEWINGS, G. J. D.; LEE, J. K. Hierarquies of Regional Sub-Structures and their Multipliers within Input-Output Systems: Miyazawa Revisited. Hitotsubashi Journal of Economics, 36: 61-70, 1993.

YAMANO, N.; AHMAD, N. The OECD Input-Output Database: 2006 Edition. STI Working Paper 2006/8, OECD, Paris, 2006. 
Annex 1. Sectors of Input-output Matrices

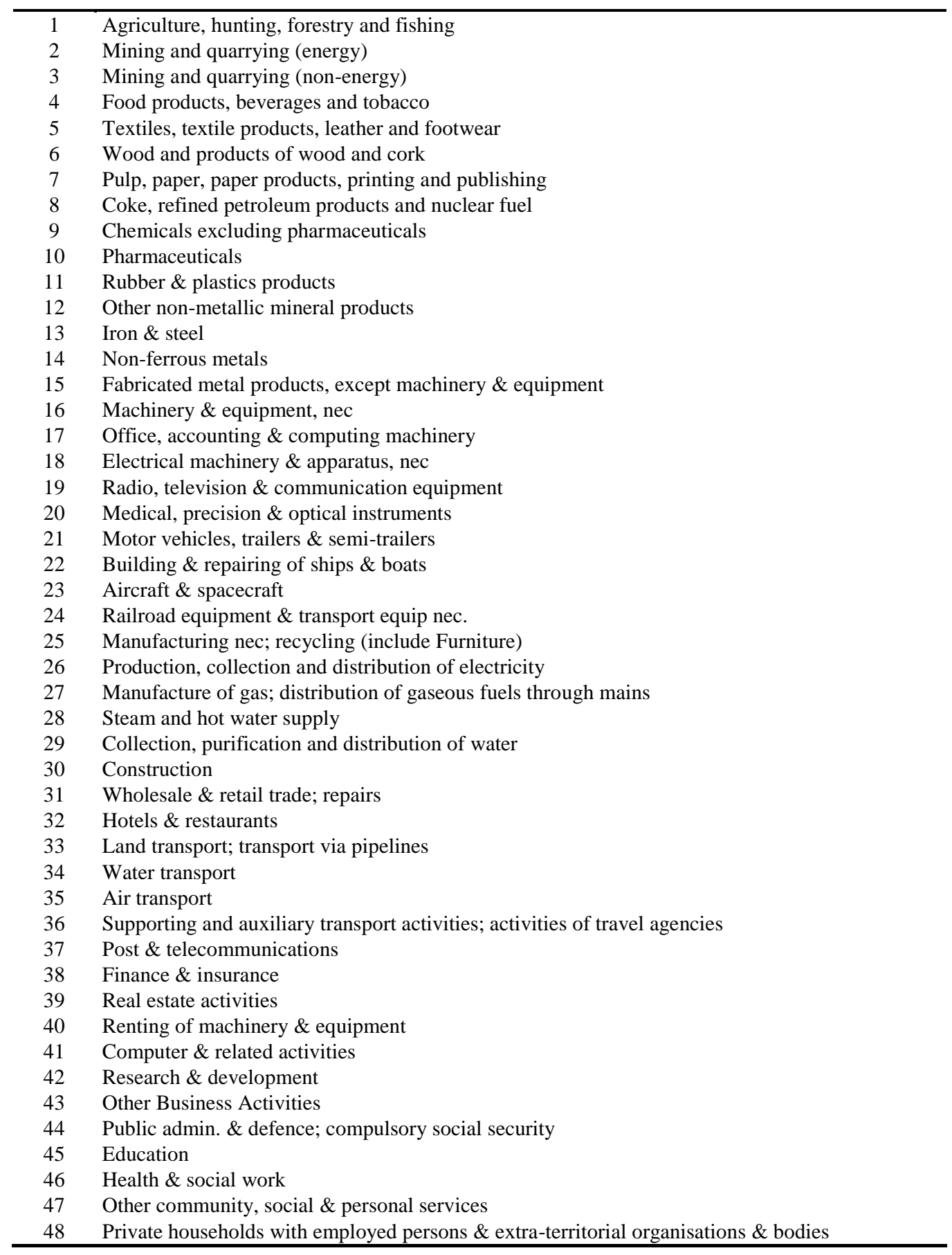


Annex 2. Countries and Years of Matrices

\begin{tabular}{lr}
\hline Country & Year \\
\hline Argentina & 1997 \\
Australia & 1999 \\
Austria & 2000 \\
Belgium & 2000 \\
Brazil & 2000 \\
Canada & 2000 \\
China & 2000 \\
Czech Republic & 2000 \\
Denmark & 2000 \\
Finland & 2000 \\
France & 2000 \\
Germany & 2000 \\
Greece & 2000 \\
Hungary & 2000 \\
India & 1999 \\
Indonesia & 2000 \\
Ireland & 1998 \\
Italy & 2000 \\
Japan & 2000 \\
Korea & 2000 \\
Netherlands & 2000 \\
New Zealand & 1996 \\
Norway & 2001 \\
Poland & 2000 \\
Portugal & 1999 \\
Slovak Republic & 2000 \\
Spain & 2000 \\
Sweden & 2000 \\
Taiwan & 2001 \\
Turkey & 1998 \\
United Kingdom & 2000 \\
USA & 2000 \\
\hline Source: Yama \\
\hline
\end{tabular}

Source: Yamano e Ahmad (2006) 